\title{
3D - Material Extrusion - Printing with Biopolymers: A Review
}

\author{
Josef Valentin Ecker, ${ }^{1, *}$, Milan Kracalik², Sabine Hild ${ }^{2}$, Andreas Haider ${ }^{1}$ \\ ${ }^{1}$ Kompetenzzentrum Holz GmbH, Science Park 2, Johannes Kepler University Linz, Altenbergerstrasse 69, 4040 Linz, Austria \\ ${ }^{2}$ Institute of Polymer Science, TNF Tower, Johannes Kepler University Linz, Altenbergerstrasse 69, 4040 Linz, Austria
}

Copyright $\odot 2017$ by authors, all rights reserved. Authors agree that this article remains permanently open access under the terms of the Creative Commons Attribution License 4.0 International License

\begin{abstract}
Additive Manufacturing represents a well-known and fast growing material processing technology. Printed part is formed by adding material layer by layer until the part is finished without requiring any additional molds. Therefore, using Additive Manufacturing can save time and costs in comparison to commercial production methods particularly when manufacturing complex prototypes or small batch series. Another advantage of Additive Manufacturing is its freedom of design. This review is focused on material extrusion, a specific Additive Manufacturing technology. It begins with a short overview of the most common materials processed with this technology. Subsequently, we discuss several processes and machine parameters in material extrusion as well as their influence on the printing process and on the final properties of the printed part. Based on this knowledge, various challenges in material extrusion are also identified. These challenges must be resolved in order to improve the material extrusion process.
\end{abstract}

Keywords Additive Manufacturing, 3D Printing, Biopolymers, Rapid Prototyping, Material Extrusion

\section{Introduction}

\section{Definition of Additive Manufacturing, Origin and Operation Method}

In the literature, different denotations for "Additive Manufacturing" (AM) can be found. Rapid Prototyping (RP), for example, covers all manufacturing methods with the aim to transform digital objects into physical parts fast and without any additional tools. The term RP has been used since 1980. Rather, any material can be added layer by layer to produce the desired component. In this way, both AM and RP are identical terms; they describe a method to produce physical parts out of digital objects.
AM was first introduced in the 1860s for use in art (e.g. photo-sculpture) and was adapted in the $1890 \mathrm{~s}$ to accommodate the topography field. Based on primal fields of application, a special procedure called "Photo-glyph recording" was developed and patented in 1951. The working principle was similar to the modern approach: a scan system was used to scan the object while a special machine was simultaneously used to build up the scanned geometry layer by layer until the scanned object was replicated successfully. This technique shows parallels to the well-known vat photo polymerization (SLA) used presently. [1, 2, 3]

\section{History of AM}

Although the first applications of AM could be found several decades ago, the big breakthrough in AM technology has taken place in the last few years. What are the reasons for this sudden progress?

Early on, one problem was the slow development of high quality machines, high performance materials and high costs for both machines and processed materials. Recently, the production time for prototypes created using AM, as well as the related costs, dropped significantly. This advancement has enabled the first commercial applications of AM.

Another reason for the late introduction of AM was that the process technology had to be developed first. This development depended on the availability of high quality sensors, automatization and data processing software. These devices had to be further developed and tested before they could work properly within an AM machine and used in a high-quality $3 \mathrm{D}$ printer.

Besides technical development and progress, media also contributed to the accelerated progress in AM. 3D printing was presented to the public as the first processing technology capable of producing parts of any shape with total freedom of design. As a result, the idea and possibilities of 3D printing rapidly spread worldwide. This public interest further motivated industrial leaders to 
develop new processing technologies, new machines and improve material processing capabilities. Although the industry was partially responsible for financing these developments, government funding contributed greatly.

Several years after the big breakthrough in 3D printing, operators now find themselves somehow disappointed. Media spread an exaggerated picture to public. As an example, the material extrusion printing machine was presented as a very simple AM machine. It was claimed that the user is able to produce parts of desired geometry, at home, without any technical background. However, this turned out to be false as the user must still define the process parameters in an appropriate way since modern machines lack self-optimization capabilities. Moreover, $\mathrm{AM}$ technologies often feature several limitations when it comes to producing large or high performance parts. This is likely due to variation in the quality of machine components.

Thus, significant progress towards process technology and material development has to be achieved. $[1,2,3,4,5$, 6]

\section{Basic Steps of AM}

In general, AM describes the production process of a specific part via a well-defined AM-technology. The starting point is an unshaped material source (e.g. powder, filament (solid polymeric plastic wire) liquid), which is oriented, arranged and shaped layer by layer. The method of construction, the geometry and the appearance of the final part is defined in a CAD-file or similar digital file format. For production of the virtual part, any CAD-software can be used. Alternatively, the file can be generated directly via $3 \mathrm{D}$ digitalization of an existing part using a 3D digitizing device. This file is then converted into a specific traveling path, which controls the movement of the 3D printer and the production process of the desired part $[1,2,3,7,8]$. Figure 1 shows the basic steps of an AM process.

\section{Processing Technologies for AM}

In contrast to conventional molding processes (which involves forming, joining, disjoining or welding parts), AM parts are created by adding material layer by layer. The accuracy of the final printed part strongly depends on the mechanical and optical properties of the printer as well as the thickness of each added layer. High precision in the layering process lessens the deviation of the printed part from the digital/virtual part and, ultimately, increases the likelihood of producing an accurate final product of high-resolution. To achieve this level of precision, good hardware components with high moving precision and well-developed software for accurate data processing are necessary. Another important factor is building time. For a meticulous part, the layer height and velocity of the print head must be kept low. The final part will consist of more layers of thin size and the printing must be carried out at a lower speed. Therefore, it is important to find a good compromise between accuracy in dimension/resolution as well as the required building time and costs for hardware/software components. [2, 3, 8, 9, 10-16, 17-19]

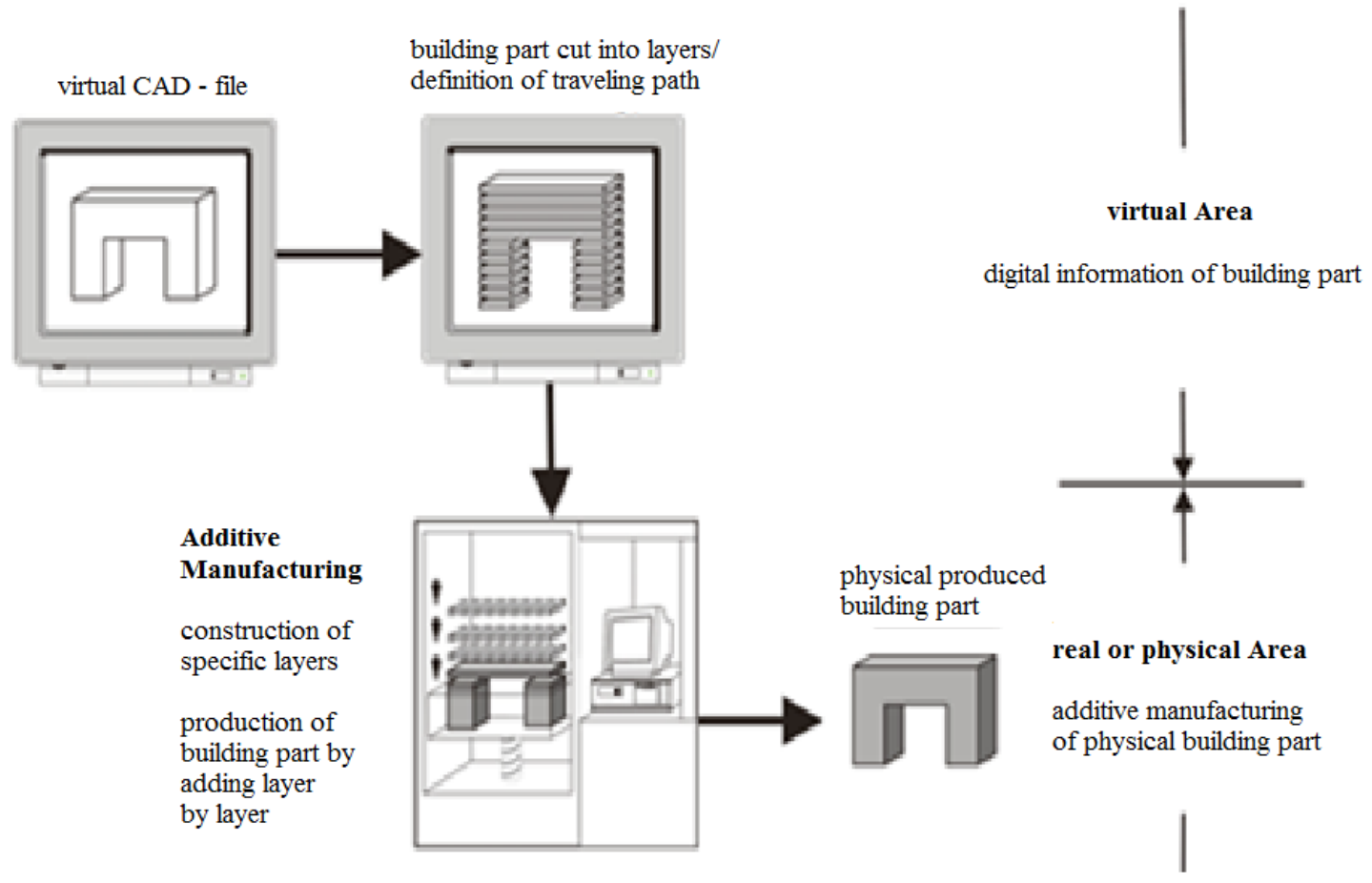

Figure 1. Basic steps of AM [4] 


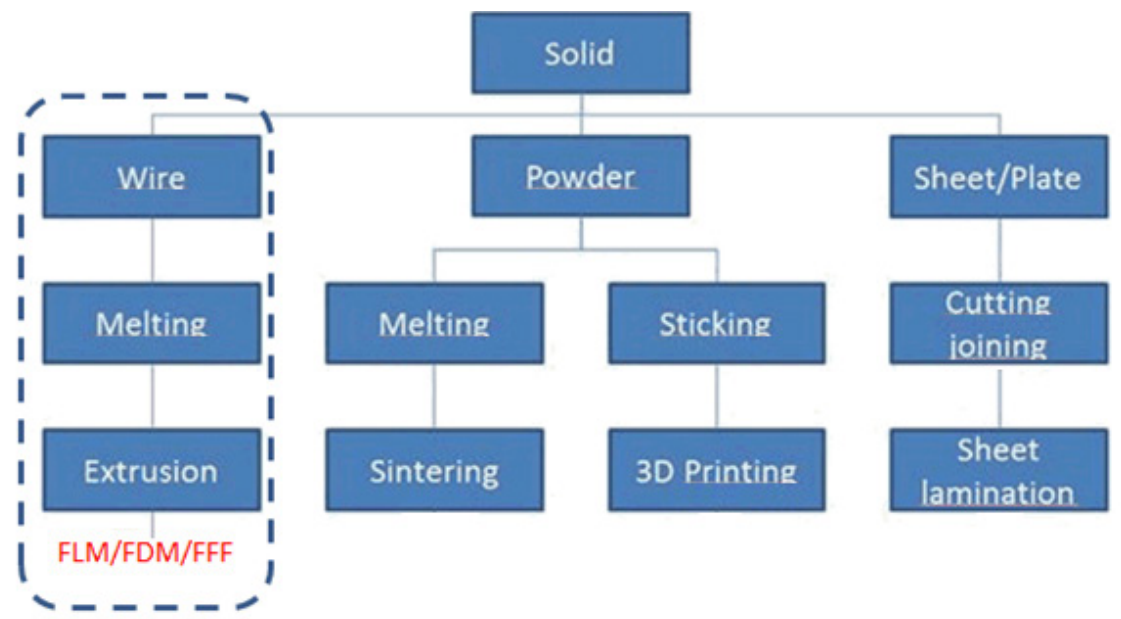

Figure 2. AM methods which can process solid source material [20]

For the production of parts using AM, different AM methods based on contrasting working principles were developed and improved over time. However, they still require further development and optimization to achieve better accuracy in printing and to improve the mechanical and optical properties of the printed parts. Another big goal in the area of $3 \mathrm{D}$ printing is to reduce the printing time for faster production. Figure 2 shows an overview of several AM methods processing solid source material:

Solid source based AM methods are the best-known and most widespread methods. The required machines and material for the processing of solid wire are affordable (the cheapest machines cost below $1000 €$, filaments cost below $50 €$ ) and there is little technical knowledge required to start running such machines. Nevertheless, advanced knowledge about the process and machine parameters is key to realizing a good print result. $[3,4,10$, $12,21]$

To enhance our scientific understanding on the process of filled polymeric materials in solid wire based printing methods, an EU-funded project has been initiated. Within this project, the basics for the development from filament production to the final part will be explored. At the end of this project, R\&D institutes will come together and create a platform to offer various services (including assistance along the whole development chain for solid-wire based printing) to companies. Accordingly, this review is focused on this additive manufacturing process and extensively investigates state-of-the-art technologies and identifies gaps in knowledge based on published literature. $[3,4,10,12,21]$

\section{Material Extrusion Printing}

\section{Definition of FLM, FDM, FFF and Material Extrusion}

In the literature, various denotations for thermoplastic extrusion-based AM technology can be found. The basic operation principle was developed by Scot Crump, a US-engineer, who filed a patent in 1989 and funded the company "Stratasys". As a next step, Stratasys filed for "FDM" (Fused Deposition Modelling) to become a protected brand. To avoid conflict in using protected acronyms, alternate denotations to FDM - such as FFF (fused filament fabrication), FLM (Fused Layer Modelling) or material extrusion - are often used. This review will stick to "material extrusion" as a synonym for the extrusion-based AM technology.

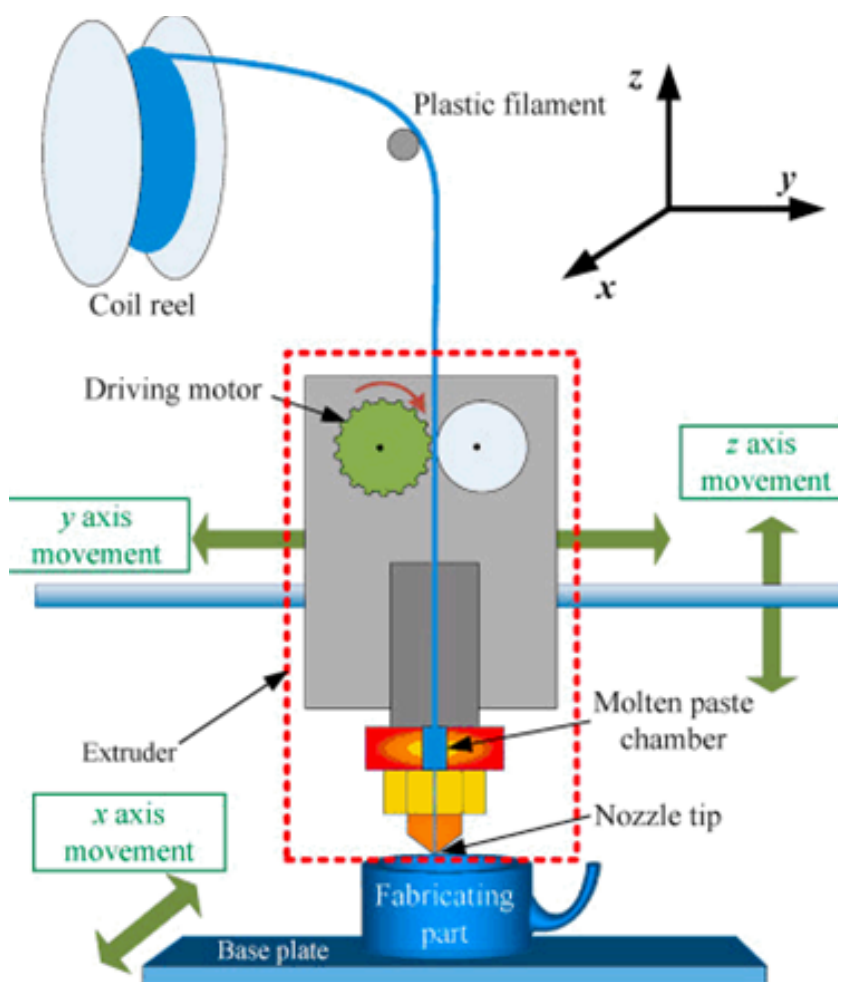

Figure 3. Scheme of FLM process [9]

The raw material used in material extrusion consists of a solid wire made out of filled and unfilled thermoplastics, also called "filaments". It is forced into the print head, 
heated and molten in a specific chamber called a hotend. As the material is melted, additional solid filament is pushed into the printing head, which creates pressure inside the hotend and forces the molten polymeric material to exit the hotend through the die. While the filament is supplied continuously to the print head and molten filaments exit the hotend, the print head moves and travels along the digital path. In this way, polymeric material is continuously deposited, creating the physical object layer by layer, as shown in Figure 3 .

During material deposition, it is of great importance that the extrusion of hot polymer melt and the traveling printing head is well concerted to each other. Furthermore, the molten extruded polymer must be deposited precisely. Any deviation will end up as an optical defect on the final part. The first layer of material is extruded on the printing platform, which also can be heated. Further layers are deposited directly on cooled down, solidified polymeric material. To ensure that there is a good connection between the existing layer and the new deposit layer, molten filaments are extruded with some contact pressure and overlap. The process is similar to a polymer welding process. The quality of weld lines between each layer is responsible for the mechanical and optical properties of the printed part. $[4,8,22,23]$

\section{Temperature Range}

Material extrusion is carried out at temperatures ranging from of $165^{\circ} \mathrm{C}$ to $300^{\circ} \mathrm{C}$. The optimal processing temperature depends on several variables: the specific properties of the polymeric material, the printing machine's hotend, the specific printing parameters and the geometry of the virtual part.

For example, natural fiber reinforced composites (NFC) should be processed at temperature levels below $200^{\circ} \mathrm{C}$ to guarantee that neither the used polymer nor the natural reinforcing component is degraded. As material extrusion works effectively at these low temperatures, NFC can be processed without any major problems.

\section{Materials Used for Material Extrusion}

Only specific materials can be processed for the material extrusion process. The following materials are mostly commonly used for 3D material extrusion printing:

- $\quad$ Polylactic acid (PLA)

- $\quad$ Acrylonitrile butadiene styrene (ABS)

- Poly methyl methacrylate (PMMA), Polycarbonate (PC), Polyamide (PA), polypropylene (PP), polystyrene (PS), polyethylene (PE)

- $\quad$ Polyvinyl acetate (PVA), High impact polystyrene (PS)

- Polyether ether ketone (PEEK), Polyetherimide (PEI)
PLA is a well-known and common thermoplastic polymeric material for material extrusion. It is a thermoplastic based on Poly lactate acid. The polymer shows biocompatibility and is, under optimal circumstances, totally biodegradable. Its glass transition temperature $\left(\mathrm{T}_{\mathrm{g}}\right)$ depends on the polymer blend but usually lies between $45^{\circ} \mathrm{C}$ and $65^{\circ} \mathrm{C}$.

Due to the following properties, PLA is an easily handled material: it shows low water vapor absorption, abrasion resistance, a smooth and hard surface as well as color fastness and is UV-light resistant. Furthermore, its thermal expansion coefficient is low.

For applications where high mechanical properties are required, PLA can be processed and blended with different fibers. It can also be blended by a second polymer phase to achieve different bulk or surface properties. There is also the possibility to add other reinforcements to the polymer and thereby change its physical and mechanical behavior.

The raw material price for $1 \mathrm{~kg}$ of PLA is about $5-10$ $€ / \mathrm{kg}$ and $20-30 € / \mathrm{kg}$ for $1 \mathrm{~kg}$ of filament. As such, it is more expensive than standard polyolefin, which costs about $1-3 € / \mathrm{kg}$. [4, 10, 11, 13, 25, 26, 27, 28]

ABS is a synthetic polymer consisting of the three monomers: acrylonitrile, 1,3-butadiene and styrene. Depending on the proportion of the three monomers, the properties of the polymerized ABS differs and can be modified and adjusted to suit the intended application. In comparison to PLA, the service temperature is much higher due to its higher glass transition temperature $\left(\mathrm{T}_{\mathrm{g}}\right)$ of $100-120^{\circ} \mathrm{C}$. When there is an application with service temperatures higher than $40^{\circ} \mathrm{C}$, ABS should be used instead of PLA to make sure the remaining mechanical properties can carry the loads. The melting temperature also depends on the proportion of the three monomers and is between $210^{\circ} \mathrm{C}$ and $260^{\circ} \mathrm{C}$. In contrast to PLA, ABS shows increased mechanical properties and higher strength.

Besides these advantages, ABS also shows some drawbacks in comparison to PLA. The thermal expansion coefficient of ABS is much higher. Therefore, the processing of ABS is different than that of PLA and often leads to big problems when using a conventional material extrusion printer. In addition to problems with high shrinkage, high processing temperatures are needed. It is also essential to use a heated platform to print on. Otherwise, the parts lose grip to the platform causing a failure to print. Material extrusion machines, which are optimized for processing of ABS, have special coated platforms or platforms with high surface roughness. It helps to improve the binding of the object to the build platform as well as to keep the overall temperature of the part higher and slow down the cooling process. In this way, thermal residual stress is reduced to a minimum. In terms of costs, ABS is about as expensive as PLA: prices for ABS filaments lie in the range of $20-40 € / \mathrm{kg}$. [2, 4, 8, $10,11,13,24,26-32]$ 
Besides these well-known and often used polymers (PLA, ABS), there are technical polymer types that have not been used extensively so far. These polymers often require advanced knowledge and special machine components to guarantee a successful print by material extrusion. Most of the time, specific adjustments must be made and several test prints must be done to identify the correct parameters for the printing process.

Nevertheless, there are technical polymeric filaments that are already working with material extrusion. Some examples include PC, PA 6.6, PMMA, PE, PP, PS, HiPS and PVA.

HiPS and PVA are materials which are used for support structures during material extrusion. As the part consists of sharp overhangs or undercuts, support structure are built up parallel to the part to support and underpin the printing of the part when necessary. These materials are well suited for this application as they can be removed completely after the print is finished. PVA can be dissolved in warm water while HiPS can be dissolved in D-Limonene oil. After the print, the part, together with the support structure, is put into the fitting solvent and left there for some hours. Moving the solvent with agitation helps to fasten the solvent procedure and save time. Using PVA or HiPS for support structures instead of the same material as used for the main part means no mechanical post-processing is necessary.

In praxis, there are some problems regarding the use of PVA or HiPS when big or thick support structures are created. They take quite a lot of time to be dissolved completely. Furthermore, problems can occur with the bonding between the support structure and the main part as some materials are not compatible with one another. Therefore, it is important to check the coupling and bonding behavior between the materials to be used for the main part and support structure when the material selection is done. When choosing PLA as the material for the main part, the use of HiPS instead of PVA is advised because of solid bonding results resulting in fewer problems while printing. Using PVA, on the other hand, may create problems like layer decoupling, rough surface creation or no binding at all.

Besides the mentioned technical polymers, there are few high temperature technical polymers as PEEK and PEI. These are mainly used for high temperature applications or fields where high mechanical performance is required. For processing such high temperature polymers a high temperature filament extruder and a special designed hotend is necessary. The processing temperature of such polymers lies between 350 and $500^{\circ} \mathrm{C}$. Most of commercial 3D printers cannot handle this temperature range and cannot process high temperature filaments at all. Besides the extrusion system and hotend, there are further requirements when processing high temperature materials. This topic is not further discussed as the funding of the project does not cope with extrusion temperatures higher than $260^{\circ} \mathrm{C} .[2,8,10,13,22,23,24$, $26,27,28,33,34]$

\section{Filled Polymeric Materials for Material Extrusion}

Apart from using different polymeric materials, there is the possibility to change the properties of the part by using additives and fillers. This results in a composite material with special properties (often with anisotropic behavior). Various fillers have been investigated (e.g. sand, brick, metal powders, plasticizers). These fillers are mostly used to change the optical appearance and surface of the produced part. Besides these fillers, reinforcements can also be added to the polymer matrix to improve the mechanical properties such as strength and stiffness. Such reinforcements can be made of fibers (e.g. glass, aramid, carbon, and cellulose), synthetic fillers of different shape (e.g. talcum, graphene, CNTs) and even biocompatible/biodegradable fillers (e.g. wood, bamboo, cork, tone, cellulose). In consideration of the big variety of polymeric materials and fillers, the final properties of the printed parts can be adapted and optimized to suit the intended application.

Nevertheless, there are some restrictions regarding the fillers of the polymeric materials used for material extrusion. The filament is melted inside the printer head's hotend and forced through a specially-designed die hole that is between $0.2 \mathrm{~mm}$ and $1 \mathrm{~mm}$ in diameter. Accordingly, there are requirements on the maximum dimension of the fillers based on the mounted die size. Failure to meet this requirement may result in significantly reduced material flow or complete blockage of the die by the filler.

Furthermore, processing reinforced or filled polymeric materials is connected to higher abrasion of the extruder, hotend and die. This leads to significantly higher wear and, therefore, results in shorter service intervals for these components. Aside from the steep costs of customized materials (often up to $100 € / \mathrm{kg}$ ), the cost of printing as well as additional maintenance costs of the machine also have to be considered.

Additionally, advanced knowledge is required when processing filled or reinforced polymeric materials as they show different material flow and bonding behaviors. They also differ in printing parameters, which have to be adjusted on the printing machine to achieve good printing results.

$[2,4,8,10,11,13,16,22-24,27-29,33-35]$

\section{Requirements for Successful Material Extrusion}

Material extrusion technology is an oft used AM method. The printed part should show high mechanical performance as well as good optical and mechanical 
properties. Considering the information presented in chapter 2, there are some challenges, which must be overcome to guarantee a printing process with good results:

\section{Quality, Homogeneity and Geometry and Stiffness of the Filament}

The geometrical and morphological properties of the filament have a big influence on the printing process and the properties of the printed object (see 3.3.4). Therefore, it is necessary to produce a homogeneous filament with defined geometry to avoid any negative influence on the printed part.

\section{Process Stability and Reproducibility}

While AM technologies are being improved and further developed all the time, we still see big problems in process stability and reproducibility of the printed parts. Even if two parts are produced by the same AM technology, using similar material and process parameters, the properties of the printed parts are not necessarily identical. This is because the process technology is sensitive to external influences. Even small changes in process parameters or in the polymeric material may lead to different properties of the printed parts. Thus, reproducibility is limited. Using different 3D software or different printing machines has further impacts on reproducibility although the geometry of the part and processed material remain the same. Furthermore, printed parts have to be post-processed and finalized mechanically to achieve satisfying products. This post-processing can also have an impact on reproducibility, but it is expected that automation can help avoid this issue.

\section{Requirements on Filament Quality}

For production of different filaments with optimal geometry and homogeneity, it is of great importance that the extrusion tool is optimized and adapted to the rheological behavior of the polymeric material. An optimal tool design for the production of filaments must be investigated to generate filaments without internal stresses and defects (e.g. voids).

\section{Number of Extruder Systems}

There are various 3D printers with different extruder systems available. If the printing machine gets two extruders or more, new possibilities come up. It would be possible to process two different materials in one print job or one material can be used for the part and a second material for support structures. Different polymeric materials could, perhaps, be printed within one layer.
Nevertheless, advanced knowledge is required to achieve good printing results. Depending on the processed materials, the optimal machine and process parameters have to be investigated. Furthermore, different material must be compatible with one another. Special requirements regarding the properties and contents of polymeric materials are currently unknown and have to be identified first.

\section{Support Material}

The support material does not belong to the printed part but might be necessary for the production of the printed part. New compatible polymeric materials for this application should be identified and analysed. In addition to the properties of the material itself, the print parameters must be optimized to involve an easily removed support material without affecting the print process.

\section{Degradation of Polymeric Material}

Polymeric material undergoes various processing steps until the part is finished. Every processing step shows an influence on the mechanical and morphological properties of the polymeric material. Degradation (e.g. by moisture, temperature) will take place and this has a negative impact on the properties of the final part. Detailed information about the quantity of degradation per processing step and possibilities to keep degradation at a minimum are yet to be investigated and should be published afterwards.

\section{Influencing Parameters for Material Extrusion}

Various parameters influencing the material extrusion process can be found. Due to interactions between these parameters, it is difficult to predict the outcome even though only a single parameter was changed. The most significant parameters can be classified as listed and are discussed below:

- Process and machine parameters

- Part design and orientation

- Material properties (filament)

- Environmental influences

\section{Process and Machine Parameters Influencing Material Extrusion}

Influence of the Printing Temperature

In a recent experiment, cubes of the same geometry were created at different temperatures $\left(\mathrm{T} 1=210{ }^{\circ} \mathrm{C}\right.$; $\mathrm{T} 2=220^{\circ} \mathrm{C}$; $\mathrm{T} 3=230{ }^{\circ} \mathrm{C}$ ). Filament made out of HiPS was processed into cubes via material extrusion. The dimensions of the cubes were measured and compared to the dimensions of the virtual part. To characterize the 
cubes' internal structure, they were cut through their center.

The resulting cubes displayed an absence of internal cavities at a printing temperature of $210^{\circ} \mathrm{C}$ and there was no deviation in geometry compared to the virtual part. As the temperature was increased to $220^{\circ} \mathrm{C}$ and above, problems with internal cavities were found. When raising the temperature from $220^{\circ} \mathrm{C}$ to $230^{\circ} \mathrm{C}$, the dimensional accuracy also reduced. This phenomenon occurred due to higher shrinkage of the part in response to a higher temperature differential between the hot melt and the environment.

To produce parts lacking internal cavities and with high dimensional accuracy, the printing temperature should be set as low as possible while still allowing successful melting and processing of the polymeric material. $[8,16$, 36-46]

\section{Influence of the Material Feed-rate and Die Output}

Other important process parameters are the material feed-rate and die output. Both parameters define how much material is forced through the small die. The flowrate is of big importance and must be correlated to the printer head's travel speed. If the output is too low, the part will feature internal cavities and defects on the surface of the printed part, resulting in a negative impact on the mechanical properties of the part. An overly high output will lead to a very rough surface on the part. Material may spill over on the surface of each printed layer, resulting in decreased dimensional accuracy and weak bonding with the subsequent layer. Furthermore, the optical properties may be low and the geometry of the printed part could be significantly different from the virtual part. It is important, therefore, to find the optimal relation between the feed-rate/output and travel speed of the print head.

When high-viscous polymeric materials are processed, it might be a good idea to increase the feed-rate. These polymers show higher pressure loss and worse flow properties, resulting in an overly low output. An increase in feed-rate may solve these problems. The correct value for the feed-rate strongly depends on the processed material and the printing machine used. $[8,20,39,40,43$, 45-48]

\section{Influence of the Layer Thickness}

The defined layer thickness significantly influences the print time. The virtual part is sliced into layers of defined thickness. The higher the thickness of each layer, the lower the number of layers. The printing time increases linearly with the number of layers. Nevertheless, it is not recommended to set the layer thickness higher than $0.4 \mathrm{~mm}$ or $80 \%$ of the diameter of the die hole to assure enough material can flow through the die. The higher the layer thickness, the lower the surface quality and the higher the surface roughness will be. Also, the resolution is poor at high layer thicknesses. Empirically, we know a good compromise between optical properties of the part and print time is a layer thickness of $0.2 \mathrm{~mm}$. [8, 20, 21, 25, 39, $45,49]$

\section{Influence of the Print Speed and Limitations}

One simple way to reduce the print time is to increase the print speed (travel speed of the print head). In relation to increasing the travel speed, the material feed-rate must be increased.

An increase in print speed should work fine up to a specific upper-limit. While reducing the print time, a higher print speed also often has a negative impact on dimensional accuracy and optical properties. Therefore, the maximum print speed depends on the technical and optical requirements of the part. The optimal print speed represents a compromise between print time and good print results.

Apart from requirements of the part, there are three main variables limiting the maximum print speed: performance of the used printer, the raster width and thermodynamic and rheological properties of filament.

\section{Performance of the Used Printer}

Characteristic variables are the stiffness and accuracy of the printer's head-travel system, the overall weight of the print head and the specific melting power of the hotend. At high traveling speed, the print head has to accelerate quickly and decelerate abruptly. Long traveling distances can be achieved easily, but small travel distances will lead to problems as fast, short movements will cause the traveling system to vibrate. These vibrations can build up and reach a resonance state resulting in dimensional inaccuracy, poor optical properties and mechanical defects with the part as well as damages to the traveling system of the printer. Therefore, the desired print speed must be below the recommended print speed of the printer's manufacturer.

Another variable derives from the melting power of the hotend. At higher print speeds, the hotend has to deliver more heat energy per unit time to cope with the higher feed-rate and material die output. The upper limit of the printing speed is limited by the maximum power of the hotend. Only melted material can exit the hotend through the die. If the melting power of the hotend is not enough, the feeding-rate of the filament will be delayed and non-constant polymer flow will be the result. For an optimal melting process, the print speed and utilization parameters of the hotend should be set below the maximum power of the hotend. In this way, there is still heat capacity left, which will lead to a stable melting process and constant extrusion rate during the print.

\section{Influence of the Raster Width}

The raster width has a great impact on the dimensional accuracy, internal cavity and surface properties of the 
printed part. The raster width describes the distance between the main coordinates of two nearby rasters. The print head puts each coordinate of the raster next to the previous one with spacing equal to the raster width. If the raster width is too high, free space will be created between the two rasters. As a result, the fabricated part will have internal cavities and surface defects. On the other hand, if the raster width is too small, overlapping will occur. This means that some parts of the new raster will lie on the previous one resulting in larger dimensions of the fabricated part with some distortion in contour. Therefore, it is important to choose the right setup for the raster width, depending on the chosen polymeric material. The best printing results feature a smooth surface and good optical and volumetric properties. $[8,20,39,43,47,50]$

Thermodynamic and Rheological Properties of the Processed Polymeric Material

Besides the performance of the printing machine itself, the type and properties of the processed polymeric material plays an important role in defining the maximum printing speed. Polymeric material with a low melt-enthalpy and low melting point requires less heat energy to be plasticized. In this case, less power from the hotend is needed to melt the polymer and, therefore, the user can increase the printing speed.

If the thermal properties of polymeric material (e.g. melting point, melt-enthalpy) and the maximum heat power of the hotend are known, the theoretical maximum printing speed can be calculated.

In addition to melt-enthalpy, the thermodynamic heat transfer properties must be considered. The solid filament enters the hotend and feeds into the hot cylinder wall. The polymeric material melts immediately. Due to the tapered design of the hotend, melted polymeric material is pushed in front of the solid filament, which improves the melt process. Nevertheless most of the solid filament is heated and melt via energy transfer through the polymeric material itself. The filament only touches the hot surface of the hotend at the outmost layers. As polymers show low heat transfer properties, the melting of the filament core requires heat and time.

This property suggests a limit in the maximum printing speed. Nevertheless, it is possible to increase the hotend temperature to improve the heat transfer through the polymer melt and speed up the melting process. On the other hand, the higher temperature of the hotend may degrade the polymeric material.

Last but not least, there is a third key variable influencing the printing speed: the viscosity of the polymeric material. The flow behaviour of the melt is directly correlated to its viscosity. Due to the tiny die hole, pressure is needed to force the melt through the die. With increasing viscosity of the polymeric material, the pressure lost through the die will increase. This pressure loss is also dependent on the volumetric flow or the forced flow speed of the melt. The pressure inside the hotend is produced via feeding of solid filament into the hotend. As the required backpressure inside the nozzle exceeds a critical value, intake problems of the filament occurs. Therefore the viscosity of the polymeric material limits the maximum flow speed due to the limited pressure build up inside the hotend. For high speed printing, it is recommended to choose a polymeric material filament with a high MFR (Melt Flow Rate). Thus, low viscosity at the processing temperature is crucial in maintaining the required pressure to produce an ideal output. [8, 21, 36-38, 45-48, 50, 51]

\section{Part Design and Orientation}

\section{Design for Material Extrusion Printing}

In addition to the process parameters, it is important to have a material extrusion optimized design of the virtual part to archive the best results. Design guidance is required and should be taken into account when the virtual part is created.

\section{Anisotropic Properties of the Printed Part}

Due to the characteristics of material extrusion, the printed objects show anisotropic properties. It is necessary to improve bonding between layers to achieve part properties which are close to those of an isotropic part. Solutions can be found in the printing process and polymeric material.

\section{Optimization Method of Printing Process}

Up to now, the printing process is very sensitive to changes in the properties of the filament. Even small differences within the same filament show influences on the part. Therefore, it is necessary to tune and adapt the printing process to the processed filament to achieve the best printing results. An easy and time saving guidance / test procedure should be developed to find the optimal processing parameters for each filament or group of filled and unfilled polymeric materials.

\section{Influence of the Part Orientation on its Mechanical Properties}

Several experiments show that the orientation of the part on the print platform has a great impact on the properties of the final part. Due to layer-composition, the printed part shows anisotropic properties. The print head moves along the specified travel path within the layer until the layer is complete. At the same time, a specific amount of polymeric material is extruded in defined relation to the travel speed.

Due to the characteristics of the process and layer-composition, the final part shows anisotropic behavior. In terms of extrusion, the part consists of continuous extruded material lines within a layer, which are aligned next to each other and partly melted together. The layers consist of polymeric lines in a direction that is 
transverse to that of the extrusion and is subsequently melted together to form a strong bond. Wherever lines and layers melt together weld lines are created. These weld lines represent significant weak points, which have a great impact on the properties of the printed part.

Due to these weld lines; there is a difference in mechanical properties between lines in the extrusion-direction and lines transverse to the extrusion-direction. This difference in mechanical strength is affected by the melting and bonding behavior of the processed polymeric material as well as by the specific printing parameters which differ from part to part.

In addition to this anisotropy, parts show different properties based on layer-direction (thickness). After one layer is finished, the next layer is added right upon the finished layer. The thickness grows with the number of printed layers, which are ultimately melted together. In most cases, the printed layer is cooled down and completely solidified before the subsequent layer is added. The subsequent layer is extruded right on top of the cold layer, which results in weaker bonding than is the case with intra-layer transverse extruded lines. Thus, the mechanical properties/strength values for printed parts are lowest in the layer-direction and are often much lower than values typically indicated in data sheets for characteristic material. The actual results strongly depend on the chosen process parameters, part orientation and processed material.

Based on knowledge regarding the anisotropic behavior of the chosen material, an optimal orientation of the part relative to the build platform can be selected. Because the mechanical properties and strength are the lowest in the layer-direction, the part should be oriented on the build platform so that minimal load occurs in this direction. Note that the difference within one layer (in extrusion-direction versus transverse extrusion-direction) is negligible as the anisotropy within a layer is fairly homogenous. [2, 8, 31, 40, 42, 48, 52-57]

\section{Influence of Material Properties on Material Extrusion}

\section{Influence of the Polymeric Filament}

In material extrusion, the material source is filament. The print head takes the filament in and forces it into the hotend. In the hotend, it is melted and exits through a tiny die hole of defined diameter. In addition to various other influencing parameters, the properties and geometry of the filament influences the printing process and properties of the produced part. The material extrusion printer requires a filament of constant and defined geometry. Most 3D printers deal with cylindrical filament with a diameter of $1.75 \mathrm{~mm} \pm 0.10 \mathrm{~mm}$. If the shape varies, it may lead to intake problems of the filament at the print head.

Before the print job is started, the real diameter of the filament must be entered into the $3 \mathrm{~d}$ printing software along with the travel code (g-code) for the print head. No commercially available printer provides an inline diameter measurement system to measure and observe the filament during a print job. Therefore, the geometry must be measured and entered into the system manually. Based on the filament diameter, the feed-rate and output is calculated. Any deviation of the filament from the entered geometrical values influences the extrusion rate at the die and cause problems during the print job. If the diameter of the filament is bigger than the entered value, the extrusion rate is higher than calculated causing too much material to be output at the die. If the diameter of the filament is smaller than calculated, the material output at the die will be too low.

Most of the time, the diameter of the filament is in the range of $1.75 \mathrm{~mm}$, but this value fluctuates. Fluctuation of the geometry of the filament may not be observed in the final part due to physical properties of the polymeric material. Due to the visco-elastic nature of polymers, a too thick filament may be compensated by compressing the material inside the hotend. When the diameter of the filament reaches $1,75 \mathrm{~mm}$ or undergoes this thickness the compressed material inside the hotend can expand again and compensate for the low material input. As a result, small fluctuations in the filament's geometry may not be visible in the final part and therefore may be neglected.

Importantly, this is only true for small deviations and smooth fluctuations in the filament's diameter. If the fluctuation is abrupt, the output will not be compensated and may result in internal cavities or defects in the part. If the diameter is too small, beyond a critical size window (below $1.6 \mathrm{~mm}$ ), further problems may happen. Normally, the solid filament enters the hotend and seals the hotend against material backflow at the intake side of the hotend. If the filament diameter is too low, melted material may exit the hotend not only through the die but also through the intake. This could lead to problems in material flow and may block the die causing a failure of the print job.

If the filament diameter is larger than entered, the output will be too high resulting in over extrusion and deviations in dimensional accuracy of the part. The upper limit of the diameter for most printers is a diameter of 2 $\mathrm{mm}$. If the filament diameter exceeds this maximum diameter value, it may cause total blockage of the die since the filament would be too big to pass through the intake hole of the hotend. Usually this leads to buckling of the filament right before the intake hole. In this event, the print head must be disassembled and cleaned before the print job can be restarted.

In addition to the geometry and shape of the filament, the quality and homogeneity of the filament is of importance for acceptable printing results. The filament is melted inside the hotend immediately prior to exiting the print die head so that no dispersive or distributive mixing occurs. The melt exits with similar properties as the original inserted filament. If the filament is not homogeneous, the final part will not show homogeneity 
either.

To sum up, the shape, geometry, quality and homogeneity of the filament has a great impact on the print process and final mechanical and optical properties of the part. Heterogeneity and deviation of the filament from the desired quality and shape will influence the final part. The best print results are achieved when using a filament of constant shape, geometry and quality. Problems during the print job or defects on the part often find their origin in imperfections of the filament. Therefore, it is recommended to have a close look at the processed filament before the print job is started. [8, 20, $39,40-46,48,50,58]$

\section{Environmental Influences on Material Extrusion}

\section{Influence of the Build Chamber Temperature}

The temperature of the environment surrounding the printed object influences the cooling process of the deposited polymeric melt during the print job. Hot melt is extruded through the hot die onto the print platform or onto the previous printed layer. The hot melt comes in contact with cold media and immediately solidifies. During solidification, the polymer undergoes a phase transition followed by a change in its volume. Due to cooling and solidification of the melt, the polymer shrinks until its temperature equals the build chamber temperature. If the melt cools down too fast, it will form an amorphous frozen outer layer but the core will have a time-delay in its cooling process. This may lead to internal residual stress placed on every layer and may negatively impact the mechanical properties or dimensional accuracy of the part. If residual stresses get too high, cracks, defects or even delamination of layers can occur.

To address this concern, it might be useful to heat up the build chamber temperature in order to slow down the cooling rate of the printed layers (similar to a temper process). A slower cooling rate will result in a more homogeneous part and higher crystalline morphology, which has a positive impact on mechanical properties and dimensional accuracy.

The build chamber temperature which is optimal for a print job strongly depends on the processed polymeric filament. For print jobs using PLA as polymeric filament, it is not obligatory to heat up the build chamber temperature, but it will help improve printing results. Polymeric material with an increased temperature expansion coefficient like $\mathrm{ABS}$, requiring tempering (desired print room temperature for ABS is about $110-$ $\left.140{ }^{\circ} \mathrm{C}\right)$. [21, 36-39, 43-47, 50, 51, 64, 65]

Influence of Humidity and Residual Moisture

Dealing with polymers the influence of humidity must be taken into account. Degradation of polymers in different forms may take place. The results are changes in mechanical and thermal properties or changes in optical properties. Reduction of tensile strength, stiffness or impact strength due to reduction of molecular weight may take place. Shift of $T_{g}$ to lower temperature can also reduce thermal stability. Changes in optical properties may include reduced light transmission behavior, yellowing and color changes.

Influence of humidity can occur during polymer processing, during application or during (intermediate) storage. Depending on the specific polymer type, the impact can be high. Polymers like PE, PP or PS show low hygroscopic behavior. The influence of humidity is not incisive. Nevertheless it is recommended to pre-dry the material bevor processing in an extruder. Humidity may not influence the material properties but problems during processing, such as voids, water inclusion in the produced polymer part or air bubbles may occur.

Other polymers behave hygroscopic, such as PA and PLA. They must be stored in a dry and dark place to avoid material degradation. This is particularly with PLA, which is known as a bio based and biodegradable polymer. Prior to any processing steps these material must be pre-dried to avoid degradation during processing. Besides degradation, further problems during processing, as already mentioned, may occur in addition. This is also true for storage and processing of filaments. Thus, it is important to study the technical data sheets of the processed material in terms of storage and processing to avoid performance reduction of the final part due to residual humidity in the material.

\section{Challenges for Successful Material Extrusion}

A well-known problem with AM technologies is the long print time. Naturally, the faster a part can be created, the higher the productivity of the process. There are various possibilities in how to reduce printing time, which will be discussed in the following section.

\section{Quality of the Printed Part vs. Production Time}

There are several parameters influencing the quality of the printed part and production time (see Chapter 3.4). For industry, both are of great importance. On the one hand, the part must be of high quality particularly in terms of dimensional accuracy and surface roughness. On the other hand, the production time should be as low as possible. To keep the required time low, the velocity of the production must be high. At a specific point, the high print speed comes at the cost of part quality. Therefore, an optimum balance between the quality of the part and the print time must be found, which depends on various machine and polymeric material parameters.

\section{Mechanical Strength and Stiffness of Printed Parts Cannot Compete with Injection Molded Parts}

Numerous experiments clearly show differences in the mechanical characteristic values between parts material 
extrusion and injection molding produced parts. Depending on the orientation of the part on the build platform as well as the processing parameters, the difference between material extrusion and injection molding can be significantly high. Generally, the maximum achieved strength by material extrusion parts is lower than that those produced by injection molding.

If process parameters are set up in an optimal way, however, material extrusion parts can reach strength values close to the strength values achieved by injection molded parts. With further development of the material extrusion process and improvement in the properties of polymeric material, it is theoretically possible to close the gap and produce parts with identical mechanical properties to the injection molding process.

This notion holds true for test samples that were printed and tested in the extrusion-direction. However, test samples that were printed and tested in the layer-direction show tremendously lower strength values than injection molded samples. This is due to the high number of weld lines between printed layers. Major improvements to the material extrusion process must, therefore, be made to reach the mechanical properties and strength values of injection molded samples. This means that the layer-by-layer bonding must be characterized in detail and all possible parameters affecting the quality and strength of the bond between layers be identified. Based on this knowledge, properties of the polymeric material and process parameters must be adjusted to approach the maximum characteristic values in the layer-direction. It is not guaranteed that the mechanical properties in the layer-direction of parts produced via material extrusion can reach the characteristic values of parts produced via injection molding. [2, 40, 42, 48, 54, 58-63, 66, 67]

\section{Standard-testing, Data Sheets and Guidelines}

Various filaments are available on the market and consist of different polymeric materials and additives. It is difficult to compare different filaments and determine which filament shows the best mechanical or optical properties for a given application. A standard test of the filament is necessary to compare filaments to each other. Decision guidelines, which would help a lot of individuals in choosing the optimal filament, must be drafted.

\section{Conclusions and Outlook}

With AM methods a new era of design and part modelling was born. While there were novel challenges compared to conventional manufacturing methods, it is now possible to produce desired parts without major restrictions in design. The part can be constructed topology optimized and all various desired functionalities can be integrated in the final part. After the print job is fulfilled the part is finished and ready to use. Furthermore there is no need to build a tool for the production of parts, so $\mathrm{AM}$ helps to save time and money. As such, AM methods show very high potential.

At the same time, however, significant improvements to the machine, software components and polymeric materials must be made to improve the mechanical and optical properties of produced parts. The performance of the printed parts must at least reach the performance of injection molded or extruded parts to cope with nowadays requirements and applications. At this point in time and to the state of the art, this is not the case.

Furthermore the print time duration must be reduced considerably. Production rate in 3D printing is low compared to conventional production methods due to its long printing time. The required printing time can be reduced significantly by an increase of the printing speed or by an increase of the printed layer height. Both lead to a higher production rate but may negatively influence the geometry, mechanical performance and surface quality of the printed part. With advanced knowledge and further developed machine software and hardware components, the printing process can be improved and optimized to increase the production rate without loss of part quality or performance.

\section{Acknowledgements}

This work was funded by the European Regional Development Fund ERDF (Europäischer Fonds für Regionale Entwicklung EFRE) and by the Upper Austrian Government within the program INTERREG V-A Österreich - Deutschland/Bayern 2014-2020.

\section{REFERENCES}

[1] Thierry Rayna, Ludmila Striukova, Technological Forecasting \& Social Change 102 (2016) 214 -224, http://dox.doi.org/10.10.1016/j.techfore.2015.07.023

[2] Gao W. Zhang Y, Ramanujan D, Ramani K, Chen Y, Williams CB, et. Al. The Status, challenges, and future of Additive Manufacturing in engineering. Computer-Aided Design (2015), http://dx.doi.org/10.1016/j.cad.2015.04.001

[3] TCKT, Polymere Werkstoffe für das

Schmelzschichtverfahren - akuteller Stand und Perspektiven SGE 03/2014

[4] Samar Jyoti Kalita, Susmita Bose, Howard L. Hosick, Amit Bandyopadhyay, Development of controlled porosity polymer-ceramic composite scaffolds via fused deposition modeling, Materials Science and Engineering C23 (2003) 611-620, http://dx.doi.org/10.1016/S0928-4931(03)00052-3

[5] J. Martinez, J.L. Dieguez, E. Ares, A. Pereira, P. Hernandez, J.A. Perez, Comparative between FEM models for FDM 
parts and their approach to a real mechanical behaviour, Procedia Engineering 63 (2013) 878-884, http://dx.doi.org/10.1016/j.proeng.2013.09.230

[6] Malte Gebler, Anton J.M. Schoot Uiterkamp, Cindy Visser, A global sustainability perspective on 3D printing technologies, Energy Policy, http://dx.doi.org/10.1016/j.enpol.2014.08.003

[7] Gebhardt A (2012). Grundlagen. RTejournal - Forum für Rapid Technologie, Vol. x0. (urn:nbn:de:0009-2-32805)

[8] Chenz GZ, Jose Estepar RS, Folch E, Onieva JO, Gangadharan S, Majid A, 3D Printing and 3D Slicer Powerful Tools in Understanding and Treating Structural Lung Disease, CHEST (2016), http://dx.doi.org/10.1016/j.chest.2016.03.001

[9] FH-Prof. Dipl.-Ing. Dr. techn. Reinhard Busch, Fakultät für Technik, FH-OÖ, Rapid Prototyping - Additive Fertigung, Faszination 3D Druck; 20.03.2014

[10] L. Lo, Q. Sun, C. Bellehumeur, P. Gu, Composite Modeling and Analysis for Fabrication of FDM Prototypes with Locally Controlled Properties, Journal of Manufacturing Processes Vol. 4/No.2 2002

[11] Weihong Zhong, Fan Li, Zuoguang Zhang, Lulu Song, Zhimi Li, Short fiber reinforced composites for fused deposition modelling, Materials Science \% Engineering A301 (2001) 125-130

[12] Du, Jun, WEI, Zhengying, WANG, Xin, WANG Jijie, CHEN, Zhen, An improved fused deposition modeling process for forming large-size thin-walled parts, Journal of Materials Processing Technology, http:/dx.doi.org /10.1016/ j.jmatprotec.2016.04.05

[13] Miquel Domingo-Espin, Josep M, Puigoriol-Forcada, Andres-Amador Garcia-Granada, Jordi L luma, Salvador Borros, Guillermo Reyes, Mechanical property characterization and simulation of fused deposition modelling Polycarbonate parts, Materials \& Design 83(2015)670-677,

http://dx.doi.org/10.1016/j.matdes.2015.06.074

[14] J. Martinez, J.L. Dieguez, E. Ares, A. Pereira, P. Hernandez, J.A. Perez, Comparative between FEM models for FDM parts and their approach to a real mechanical behaviour, Procedia Engineering 63 (2013) 878-884, http://dx.doi.org/10.1016/j.proeng.2013.09.230

[15] Ziegelmeier,S., Christou, P., Wöllecke, F., Tuck, C., Goodridge, R., Hague, R., Krampe, E., Wintermantel, E., An experimental study into effects of bulk and flow behaviour of Laser Sintering polymer powders on resulting part properties, Journal of Materials Processing Technology (2014), http://dx.doi.org/10.1016/j.jmatprotec.2014.07.029

[16] Dietmar Drummer, Katrin Wudy, Maximilian Drexler, Influence of energy input on degradation behaviour of plastic components manufactured by selective laser melting, Physics Procedia 56 (2014) 176-183, http://dx.doi.org/10.1016/j.phpro.2014.08.160

[17] Eric Barnett, Clement Gosselin, Large-Scale 3D Printing With A Cable-Suspended Robot, Additive Manufacturing (2015), http://dx.doi.org/10.1016/j.addma.2015.05.001

[18] Robert J.A. Allen, Richard S. Trask, An Experimental demonstration of effective Curved Layer Fused Filament Fabrication utilising a parallel deposition robot, Additive Manufacturing 8)2015)78-87, http://dx.doi.org/10.1016/j.addma.2015.09.001

[19] Debapriya Chakraborty, B. Aneesh Reddy, A. Roy Choudhury, Extruder path generation for Curved Layer Fused Deposition Modeling, Computer-Aided Design 40 (2008) 235-243, http://dx.doi.org/10.1016/j.cad.2007.10.014

[20] Kaveh, Mahdi, Hemasian Etefagh, Ardeshir Badrossamay, Mohsen, Optimization of the Printing Parameters Affecting Dimensional Accuracy and Internal Cavity for HIPS Material Used in Fused Deposition Modeling Processes. Journal of Materials Processing Technology $\mathrm{tttp}: / /$ dx.doi.org/10.1016/j.jmatprotec.2015.07.012

[21] Charoula Kousiat za, Dimitris Karalekas, In-situ monitoring of strain and temperature distributions during fused deposition modeling process, Materials and Design 97 (2016) 400-406, http://dx.doi.org/10.1016/j.matdes.2016.02.099

[22] O.S. Carneiro, A.F. Silvia, R. Gomes, Fused deposition modeling with polypropylene, Materials \& Design 83(2015)768-776, http://dx.doi.org/10.1016/j.matdes.2015.06.053

[23] Walter Castro smith, Richard W. Dean, Structural characteristics of fused deposition modeling polycarbonate material, Polymer Testing 32(2013)1306-1312, http://dx.doi.org/10.1016/j.polymertesting.2013.07.014

[24] A. Le Duigou, M. Castro, R. Bevan, N. Martin, 3D printing of wood fibre biocomposites: From mechanical to actuation functionality, Materials and Design 96 (2016) 106-114, http://dx.doi.org/10.1016/j.matdes.2016.02.018

[25] Zhongzhong Chen, Dichen Li, Bingheng Lu, Yiping Tang, Minglin Sun, Songfen $\mathrm{Xu}$, Fabrication of osteo-structure analogous scaffolds via fused deposition modeling, Scripta Materialia 52 (2005) 157-161, http://dx.doi/10.1016/j.scriptamat.2004.08.006

[26] Fuda Ning, Weilong Cong, Jingjing Qiu, Junhua Wei, Shiren Wang, Additive Manufacturing of carbon fiber reinforced thermoplastic composites using fused deposition modeling, Composite Part B 80 (2015) 369-378, http://dx.doi.org/10.1016/j.composite.sb.2015.06.013

[27] Rupert Wimmer, Bernhard Steyrer, Josef Woess, Norbert Mundigler, 3D printing and wood, Pro Ligno, ISSN-L 1841-4737,

https://www.researchgate.net/publication/286921783 3D P RINTING_AND_WOOD, 08.02.2017

[28] Ivica Duretek1, Ulrich Müller, Stefan Veigel, Andreas Haider, Stephan Frybort, Clemens Holzer, Neue additive Produktionstechnologien für die Holzindustrie, Poster Montan Universität Leoben, 08.02.2017

[29] M. Nikzad, S.H. Masood, I. Sbarski, Thermo-mechanical properties of a highly filled polymeric composites for Fused Deposition Modeling, Materials and Design 32 (2001) 3448-3456, http://dx.doi.org/10.1016/j.matdes.2011.01.056

[30] Peng Wu, Jun Wang, Xiangyu Wang, A critical review of the use of 3-D printing in the construction industry, Automation in construction 68(2016)21-31, http://dx.doi.org/10.1016/j.atom.2016.04.005 
[31] Alvaro Goyanes, Usanee Det. Amornrat, Hie Wang, Abdul W. Basist, Simon Gaisford, 3D Scanning and 3D Printing as Innovative Technologies for Fabrication Personalized Topical Drug Delivery Systems, Journal of Controlled Release (2016),

http://dx.doi.org/10.1016/j.jconrel.2016.05.034

[32] Raasch J., Ivey M, Aldrich D, Nobes DS, Ayranci C, Characterization of Polyurethane Shape Memory Polymer Processed by Material extrusion Additive Manufacturing, Addit Manuf (2015),

http://dx.doi.org/10.1016/j.addma.2015.09.004

[33] M. Vaezi, S. Yang, Freeform fabrication of nanobiomaterials using 3D printing, Woodhead Publishing (2014), http://dx.doi.org/10.1533/9780857097217.16

[34] Birtchnell T, et. al., 3D printing and the third mission: The university in the materialization of intellectual capital, Technol. Forecast Soc. Change (2016), http://dx.doi.org/10.1016/j.techfore.2016.03.014

[35] Toshiyuki Kida, Tomoya Ohta, Kenta Kondo, Mitsuru Akashi, Fabrication of poly(vinyl alcohol)s (PVAs) nanotubes through the fusion of nanocapsules composed PVAs multilayer films, Polymer (2014)1-7, http://dx.doi.org/10.1016/j.polymer.2014.04.043

[36] Cline Bellehumeur, Longmei Li, Qian Sun, Peihua Gu, Modeling of Bond Formation Between Polymer Filaments in the Fused Deposition Modeling Process, Journal of Manufacturing Processes Vol.6/No. 2; 2004

[37] Ziegelmeier,S., Christou, P., Wöllecke, F., Tuck, C., Goodridge, R., Hague, R., Krampe, E., Wintermantel, E., An experimental study into effects of bulk and flow behaviour of Laser Sintering polymer powders on resulting part properties, Journal of Materials Processing Technology (2014), http://dx.doi.org/10.1016/j.jmatprotec.2014.07.029

[38] Tao Peng, Analysis of Energy Utilization in 3D Printing Processes, Procedia CIRP 40 (2016) 62-67, http://dx.doi.org/10.1016/j.procir.2016.01.055

[39] L.-T. Lim, R. Auras, M. Rubino, Processing technologies for poly(lactic acid), Progress in Polymer Science 33(2008) 820-852,

http://dx.doi.org/10.1016/j.progpolymsci.2008.05.004

[40] Caterina Casavola, Alberto Cazzato, Vincenzo Moramarco, Carmine Pappalettere, Orthotropic mechanical properties of fused deposition modelling parts described by classical laminate theory, Materials and Design 90(2016)453-458, http://dx.doi.org/10.1016/j.matdes.2015.11.009

[41] P.J.Nunez, A. Rivas, E. Garcia-Plaza, E. Beamud, A.Sanz-Lobera, Dimensional and surface texture characterization in Fused Deposition Modeling (FDM) with ABS plus, Procedia Engineering 132(2015)856-863, http://dx.doi.org/10.1016/j.proeng.2015.12.570

[42] Zixiang Weng, Jianlei Wang, T. Senthil, Lixin Wu, Mechanical and thermal properties of ABS/montmorillonite nanocomposites for fused deposition modeling 3D printing (2016), http://dx.doi.org/10.1016/j.matdes.2016.04.045

[43] Omar Ahmed; phamed, Syed Hasan Masood, Jahar Lal Bhowmik, Optimization of fused deposition modeling process parameters for dimensional accuracy using I-optimality criterion, Measurement 81(2016)174-196, http://dx.doi.org/10.1016/j.measurement.2015.12.011

[44] M.Faes, E. Ferraris, D. Meons, Influence of inter-layer cooling time on the quasi-static properties of ABS components produced via Fused Deposition Modelling, Procedia CTRP 42(2016)748-753, http://dx.doi.org/10.1016/j.procir.2016.02.313

[45] Mahmood, Shahrain, Talamona, Didier, Goh, Kheng Lim, Qureshi, A.J., Fast Deviation Simulation for Fused Deposition Modeling process, Procedia CIRP 43(2016), 327-332, http://dx.doi.org/10.1016/j.procir.2016.02.004

[46] Brian Derby, Additive Manufacture of Ceramics Components by Inkjet Printing, Engineering 2015, 1(1): 113-123, DOI:10,15302/J-ENG-2015014

[47] Joseph Madamesila, Philip McGeachy, J. Eduardo Villarreal Barajas, Rao Khan, Characterizing 3D printing in the fabrication of variable density for phantoms quality assurance of radiotherapy, Physica Medica (2015), doi: 10.1016/j.ejmp.2015.09.013

[48] M.R.Karamooz Ravari, M. Kadkhodaei, M. Badrossamay, R. Rezaei, Numerical Investigation on mechanical properties of cellular lattice structures fabricated by fused deposition modeling, International Journal of Mechanical Sciences, http://dx.doi.org/10.1016/j.ijmecsci.2014.08.009

[49] Alberto Broschetto, Luana Bottini, Design for manufacturing of surfaces to improve accuracy in Fused Deposition Modeling, Robotics and Computer-Integrated Manufacturing 37(2016)103-114, http://dx.doi.org/10.1016/j.rdm.2015.07.005

[50] Roberson DA, Perez ART, Shemelya CM, Rivera A, MacDonald E, Wicker RB, Comparison of Stress Concentrator Fabrication for 3D Printed Polymeri Izod Impact Test Specimens, Addit Manuf (2015), http://dx.doi.org/10.1016/j.addma.2015.05.002

[51] Dietmar Drummer, Katrin Wudy, Maximilian Drexler, Influence of energy input on degradation behaviour of plastic components manufactured by selective laser melting, Physics Procedia 56 (2014) 176-183,

http://dx.doi.org/10.1016/j.phpro.2014.08.160

[52] O.S. Carneiro, A.F. Silvia, R. Gomes; Fused deposition modelling with polypropylene, Material \& Design 83 (2015) 768-776; http://dx.doi.org/10.1016/j.matdes.2015.06.053

[53] Nicolas Gardan, Alexandre Schneider, Topological optimization of internal patterns and support in Additive Manufacturing, Journal of Manufacturing Systems (2014), http://dx.doi.org/10.1016/j.jmsy.2014.07.003

[54] Zhenzhen Quan, Zachary Larimore, Amanda Wu, Jianyong Yu, Xiaohong Qui, Mark Mirotznik, Jonghwan Suhr, Joon-Hyung Byun, Youngseok Oh, Tsu-Wei Chou, Microstructural design and Additive Manufacturing and characterization of 3D orthogonal short carbon fibre/acrylonitrile-butadiene-styrene preform and composite Composites Science and Technology 126(2016)139-148, http://dx.doi.org/10.1016/j.composcitech.2016.02.021

[55] Jae-Won Choi, Francisco Medina, Chiyen Kim, David Espalin, David Rodriguez, Brent Stucker, Ryan Wicker, Development of a mobile fused deposition modeling system with enhanced manufacturing flexibility, Journal of Materials Processing Technology 211(2011)424-432, 
http://dx.doi.org/10.1016/j.jmatprotec.2010.10.019

[56] K. Thrimurthulu, Pulak M. Pandey, N. Venkata Reddy, Optimum part deposition orientation in fused deposition modeling, International Journal of Machine Tools \& Manufacture 44(2004)585-594,

http://dx.doi.org/10.1016/j.ijmachtools.2003.12.004

[57] Alberto Boschetto, Luana Bottini, Francesco Veniali, Finishing of Fused Deposition Modeling parts by CNC machining, Robotics and Computer-integrated Manufacturing 41(2016)92-101,

http://dx.doi.org/10.1016/j.rc.im.2016.03.004

[58] Torrado AR, Shemelya CM, English JD, Lin Y, Wicker RB, Roberson DA, Characterizing the Effect of Additives to ABS on the Mechanical Property Anisotropy of Specimens Fabricated by Material extrusion 3D Printing, Addit Manuf (2015), http://dw.doi.org/10.1016/j.addma.2015.02.001

[59] Michael Dawoud, Iman Taha, Samy, J. Ebeid; Mechanical behaviour of ABS: An experimental study using FDM and injection moulding techniques, Journal of Manufacturing Processes, http://dx.doi.org/10.1016/j.jmapro.2015.11.002

[60] Di Zhang, Baihong Chi, Bowen Li, Zewen Gao, Yao Du, Jinbao Guo, Jie Wei, Fabrication of highly conductive graphene flexible circuits by 3D printing, Synthetic Metals 217 (2016) 79-86,

http://dx.doi.org/10.1016/j.synthmet.2016.03.014

[61] S.H. Masood, W.Q. Song, Development of new metal/polymer materials for rapid tooling using Fused deposition modeling, Materials and Design 25(2004)587-594,

http://dx.doi.org/10.1016/j.matdes.2014.02.009
[62] Brunello G, Sivolella S, Meneghello R, Ferroni L, Gardin C,Piattelli A, Zavan B, Bressan E, Powder-based 3D printing for bone tissue engineering, Biotechnology Advances (2016),

http://dox.doi.org/10.1016/j.biotechadv.2016.03.009

[63] F.S. Sematov, K.V. Niaza, A.A Sephaskin, S.D. Kaloshkin, Low-cycle fatigue behaviour of 3d-printed PLA-based porous scaffolds, Composites Part B 97(2016)193-200, http://dx.doi.org/10.1016/j.compositesb.2016.04.067

[64] Brett. P. Conner, Guha P. Manogharan, Ashley N. Martof, Lauren M. Rodomsky, Caitlyn M. Rodomsky, Dakasha C. Jorda, James W. Limperos, Making sense of 3-D printing: Creating a map of Additive Manufacturing products and services, Additive Manufacturing (2014), http://dx.doi.org/10.1016/j.addma.2014.08.005

[65] Blanka A Szost, Sofiane Terzi, Filomeno Martina, Didier Boisselier, Anastasiia Prytuliak, Thilo Pirling, Michael Hofmann, David J. Jarvis, A comparative study of Additive Manufacturing techniques: Residual stress and microstructural analysis of CLAD and WA AM printed Ti-6Al-4V components, (2015), http://dx.doi.org/10.1016/j.matdes.2015.09.115

[66] Yas Khalil, Adam Kowalski, Neil Hopkinson, Influence of energy density on flexural properties of laser-sintered UHMWPE, Additive Manufacturing 10(2016)67-75, http://dx.doi.org/10.1016/j.addma.2016.03.002

[67] Al C. de Leon, Qiyi Chen, Napolabel B. Palaganas, Jerome O. Palaganas, Jill Manapat, Rigoberto C. Advincula, High performance polymer nancomposites for Additive Manufacturing applications (2016), http://dx.doi.org/10.1016/j.reactfunctpolym.2016.04.010 